\title{
AN INTEGRATED MATHEMATICAL MODEL FOR CHEMICAL OXYGEN DEMAND (COD) REMOVAL IN MOVING BED BIOFILM REACTORS (MBBR) INCLUDING PREDATION AND HYDROLYSIS
}

\author{
Marta Revillaa, Berta Galán ${ }^{b}$ Javier R. Viguri ${ }^{\text {** }}$
}

${ }^{a}$ SNIACE, Carretera de Ganzo S/N 39300, Torrelavega, Cantabria, Spain.

${ }^{b}$ Green Engineering \& Resources Research Group (GER). Department of Chemical and Process \& Resources Engineering. ETSIIT. University of Cantabria. Avenida Los Castros s/n. 39005, Santander, Cantabria, Spain.

*Corresponding author: Tlf: 30-942-201589; Fax: 30-942-206706, vigurij@unican.es

\section{ABSTRACT}

An integrated mathematical model is proposed for modelling a moving bed biofilm reactor (MBBR) for removal of chemical oxygen demand (COD) under aerobic conditions. The composite model combines the following: (i) a one-dimensional biofilm model, (ii) a bulk liquid model, and (iii) biological processes in the bulk liquid and biofilm considering the interactions among autotrophic, heterotrophic and predator microorganisms. Depending on the values for the soluble biodegradable COD loading rate (SCLR), the model takes into account a) the hydrolysis of slowly biodegradable compounds in the bulk liquid, and b) the growth of predator microorganisms in the bulk liquid and in the biofilm. The integration of the model and the SCLR allows a general description of the behaviour of COD removal by the MBBR under various conditions. The model is applied for two in-series MBBR wastewater plant from an integrated cellulose and viscose production and accurately describes the experimental 
concentrations of COD, total suspended solids (TSS), nitrogen and phosphorous obtained during 14 months working at different SCLRs and nutrient dosages. The representation of the microorganism group distribution in the biofilm and in the bulk liquid allow for verification of the presence of predator microorganisms in the second reactor under some operational conditions.

Keyword: mathematical model; biological treatment; moving bed biofilm reactor (MBBR); hydrolysis; predation; pulp and viscose wastewater.

A moving bed biofilm reactor (MBBR) is a type of biofilm technology used for wastewater treatment (Kaindl, 2010). In such a reactor, the biomass grows as a biofilm on small carrier elements that move around in the reactor maintaining the biomass per unit volume at a high level. In aerobic processes, the biofilm carrier movement is effected by blowers. Therefore, the MBBR process has the advantages of attached and suspended growth systems (Qiqi et al., 2012). A key characteristic of MBBR reactors is not only the increase in the effective carrier area that thereby directly contributes to a larger biofilm but also that it allows good conditions for the transport of substrates into the biofilm (Mašic et al., 2010). Because of the extremely compact high-rate process, the hydraulic retention time (HRT) in the MBBR is low (Ødegaard, 2006). Moreover, it

47 is a continuously operating, non-cloggable biofilm reactor with no need for 48 backwashing, low head-loss and a high specific biofilm surface area (Rusten et al., 2006).

MBBR technology has been successfully applied to many types of wastewater including paper mill wastewater (Hosseini and Borghei, 2005), pharmaceutical industry 
52 wastewater (Lei et al., 2010), municipal wastewater (Rusten et al., 1998), and fish farm

53 wastewater (Rusten et al., 2006) and has been utilized under aerobic and anoxic

54 conditions (Barwal and Chaudhary, 2014; Borkar et al., 2013).

55 Different applications require different configurations using one or more reactors in56 series for COD removal, nitrification and nutrient removal (Ødegaard, 1999). The type

57 of microorganisms in these reactors depends on the conditions under study such as the

58 origin of the wastewater, the treatment process, and the nutrient dosage, among others.

59 Modelling is an important step for the synthesis, design and decision making related to

60

61

62 wastewater treatment processes. For biological wastewater treatment, a mathematical model can be used to predict the performance of a biological treatment plant, to determine important variables and critical parameters and/or to help with troubleshooting. A model that describes the MBBR process must include the biological processes in the biofilm and the bulk liquid because the biomass exists in two forms, suspended and attached to a carrier.

For general purposes, the biofilm model by Wanner and Gujer is a great tool for understanding biofilm processes in a quantitative manner (Wanner, 1996). Moreover, this type of model is generally adequate to describe a macroscopic conversion (Wanner et al., 2006) in a biofilm system and gives a reasonable description of the layered biofilm structure (van Loosdrecht et al., 2002; Mašic, 2013). Biological processes describing the interaction between autotrophic and heterotrophic microorganisms are commonly considered by activated sludge models (ASM).

The ASM models consider bacteria as the sole active biomass. The activities of all other microbial community members (protozoa, metazoa, phages, etc.) are hidden in a simple 
decay process responsible for the reduction of active biomass. This decay process is the sum of several independent processes such as maintenance, lysis due to phage infection and predation (van Loosdrecht and Henze, 1999).

The inclusion of predation is not necessary for the successful use of current activated sludge models (Moussa et al., 2005). However, the role of predators clearly affects the performance of a treatment plant and can be especially critical for obtaining a good quality effluent with low suspended solids (Tamis et al., 2011). In the moving bed process, the type of biofilm that develops depends on the organic loading rate applied (van Haandel and van der Lubbe, 2012). Kinner and Curds, 1987, examined the predators communities inhabiting RBC biofilms exposed to various organic loading rates; predators were observed mainly in compartments with low loadings.

Despite many studies of the microbial ecology of activated sludge systems and mathematical modelling, little work has been reported on the interaction between bacteria and other microorganisms in the microbial community of activated sludge, especially the role of protozoa (van Loosdrecht and Henze, 1999). The role of protozoa in activated sludge has been investigated by authors such as Moussa et al., 2005; Ni et al., 2009 and 2011; Hao et al., 2011, who developed a simple procedure for the determination of the activity of these predators in suspended mixed cultures. These authors proposed a model to describe a mixed culture in which bacteria and predators (protozoa and metazoa) coexist. In this paper, the predation process is based on the studies of Moussa et al., 2005 and Hao et al., 2011, that simplify the description of the complex reality of the predator-prey relationship, including all types of predators in a single type and assuming that the predation process is a function of the bacterial concentration. 
However, no work has included the predation phenomena in a mathematical model for an MBBR. Taking into account the different origins and characteristics of wastewater that can be treated in an MBBR plant and the different possible plant configurations, a general model of an MBBR process requires the inclusion of the predation mechanism.

This work presents a model that considers the interaction between bacteria and predator microorganisms in the MBBR process. The integrated mathematical model for MBBR proposed in this work combines the following: (i) biological processes describing the interaction between autotrophic, heterotrophic and predator microorganisms via the model of Moussa et al., 2005; (ii) a biofilm model by Wanner and Gujer, 1986; and (iii) a bulk liquid model (Mašic et al., 2010). Because the proposed model can be useful for wastewaters of different origins, plant configurations and operational conditions, the SCLR values (soluble COD loading rate) proposed by Odegaard, 1999 are taken into account to consider the predation growth mechanism in an MBBR reactor. Similarly, the reference values proposed by Helness and Odegaard, 2005, are taken into account to consider the hydrolysis in the bulk liquid. Finally, the regeneration of nutrients due to predators is also considered in the model (Lindblom, 2003).

Wastewater from the pulp and paper industry is characterized by a high COD content that can range from approximately 1000 to $4200 \mathrm{mg} / \mathrm{l}$ (Swamy et al., 2011). In general, this type of wastewater contains lignin (40\%), carbohydrates (40\%) and extractives (20\%). The activated sludge process is one of the most common systems for the biological treatment of pulp and paper industry effluent; however, the main disadvantage of an AS process is the bulking of the sludge (Rankin et al., 2007). The pre-treatment of wastewater that has a high organic load with biofilm formation systems such as MBBR is used to control the phenomenon of bulking. In the pulp and paper industry, modelling of a biological treatment plant can be used to develop more efficient 
operational conditions and can help determine a more efficient nutrient dosage (Boltz et al., 2011; Lindblom, 2003).

126 In this work, the proposed model is applied to a full-scale MBBR plant that treats

127 wastewater from a cellulose and viscose industrial plant with large amounts of organic matter.

\section{Integrated Mathematical Model for MBBR}

The integrated mathematical model presented in this paper is a multi-species and multisubstrate biofilm and bulk liquid model for an MBBR reactor.

The state variables of the integrated model proposed are composed of the concentrations of soluble compounds $\left(S_{i}\right)$ and particulate compounds $\left(\mathrm{X}_{\mathrm{i}}\right)$ (Henze et al., 2000). The nomenclature for the model state variables is given in Table 1.

The integrated mathematical model takes into account biological conversion processes observed in Figure 1, which describes the transformation process and the interactions

137 between three groups of microorganisms (i.e., autotrophs, heterotrophs and predators). The stoichiometric matrix and process rate equations for all of the processes in the integrated mathematical model can be found in Table 2 and Table 3, respectively, and the kinetic, stoichiometric and other parameters used in the integrated model are 141 described in Table 4.

142 All particulate compounds in the model have been expressed as COD fractions, except

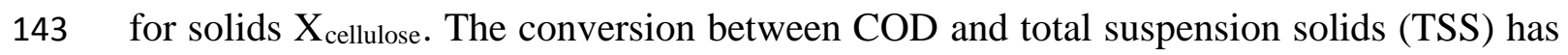
144 been evaluated assuming stoichiometric conversion parameters of 0.75 and 0.90 gTSS/g 145 COD (Boltz et al., 2011). TSS, filtered COD (COD $f)$ and total nitrogen (TN) have not 
146 been introduced as variables but were computed from the state variables by equations 1 ,

$147 \quad 2$ and 3, respectively.

148 TSS $=\left(0.75 \mathrm{X}_{\mathrm{I}}+0.75 \mathrm{X}_{\mathrm{S}}+0.90 \mathrm{X}_{\mathrm{H}}+0.90 \mathrm{X}_{\text {Aut }}+0.90 \mathrm{X}_{\text {predators }}\right)+\mathrm{X}_{\text {cellulose }}$

$149 \mathrm{COD}_{\mathrm{f}}=\mathrm{S}_{\mathrm{F}}+\mathrm{S}_{\mathrm{A}}+\mathrm{S}_{\mathrm{I}}$

$150 \quad \mathrm{TN}=\mathrm{S}_{\mathrm{NO} 3}+\mathrm{S}_{\mathrm{NH} 4}+\mathrm{S}_{\mathrm{ND}}$

\subsection{Biological processes}

152

\subsubsection{Predator growth}

The impact of predator microorganisms has been investigated in MBBR microbial communities, and it has been found that even minor operating condition changes could cause a dramatic shift in the composition of these predators (Goode, 2010; Fried et al., 2000). Authors such as Villareal et al., 1975 and Kinner and Curds, 1987 have conducted studies in which organic material is either low or the limiting substrate. These authors showed that the number of bacteria increased until a maximum value was reached due to the depletion of organic material, and later, the number of bacteria decreased and that of the predators increased. Consequently, in this study, the different SCLR values proposed by Ødegaard, 1999 have been considered to evaluate the presence of predators in the biofilm and the bulk liquid of an MBBR reactor, as shown in Figure 2. Other authors such as van Haandel and van der Lubbe, 2012, used the same classification.

Predator growth is included in the proposed model according to Moussa et al., 2005, who proposed that $i)$ the predators grow aerobically on the degradable $\left(1-f_{X I}\right)$ fraction of the heterotrophic and autotrophic bacteria, and ii) the predation rate is a function of the bacterial concentration. 
170 The hydrolysis of slowly biodegradable compounds increases the readily biodegradable 171 soluble compounds $\left(S_{F}\right)$ available to bacteria (Morgenroth et al., 2002). Direct contact

172 between slowly biodegradable compounds and microorganisms is necessary.

173 Because the model proposed in this work will be used for wastewater from the pulp and 174 paper industry, two types of slowly biodegradable compounds have been defined: i) $175 \mathrm{X}_{\text {cellulose }}$ and ii) $\mathrm{X}_{\mathrm{S}}$ (Morgenroth et al., 2002). Hydrolysis of $\mathrm{X}_{\text {cellulose }}$ strongly depends on the sludge retention time (Ruiken et al., 2013). Because in MBBR reactors the sludge retention time is short and the cellulose fibres are large, it is assumed that $\mathrm{X}_{\text {cellulose }}$ is not hydrolysed and passes through the MBBR reactors unconverted.

Slowly biodegradable organic compounds $\left(\mathrm{X}_{\mathrm{S}}\right)$ do not diffuse into the biofilm, and it is assumed that the hydrolysis takes place in the bulk liquid (Rohold and Harremoës, 1993; Larsen and Harremoës, 1994).

Hydrolysis in the bulk liquid is simulated depending on the SCLR value (Helness and Ødegaard, 2006) as shown in Figure 2.

\subsection{Biofilm model}

The biofilm model in this study is based on Wanner and Gujer (1986) (Goode, 2010; Mašic, 2013), and it i) describes the dynamics and spatial distribution of the microbial species and substrates in the biofilm, ii) predicts the evolution of the biofilm thickness and iii) describes detachment of the biomass due to sloughing and shear stress. The following assumptions have been made regarding the biofilm: 
ii. The introduction of a slowly biodegradable compound $\left(\mathrm{X}_{\mathrm{S}}\right)$ is considered as a particulate compound in the biofilm (Vanhooren, 2001).

iii. The biofilm grows perpendicular to the substratum.

iv. Monod kinetics are used to describe the conversion rate of a soluble compound and the growth and inactivation of the microorganism groups.

v. The biofilm and the suspended biomass in the bulk liquid are governed by similar kinetic parameters.

vi. The attachment rate of the suspended solids in the bulk liquid to the biofilm surface has not been considered because the net balance of solids indicates that detachment is a more significant process (Goode, 2010).

2.2.1. Mass balance for the particulate compounds by the volume fraction in the biofilm

Equations 4-10 describe the mass balance for the particulate compounds (i) by volume fraction $\mathrm{f}_{\mathrm{i}}(\mathrm{t}, \mathrm{z})$ in the biofilm and the boundary conditions:

$\frac{d f_{i}(t, z)}{d t}=\left[U o_{i}(t, z)-\bar{U}_{o}(t, z)\right] f_{i}(t, z)-U(t, z) \frac{d f_{i}(t, z)}{d z}$

$\mathrm{i}=\mathrm{S}, \mathrm{H}$, Aut, I and predators.

$\overline{\mathrm{U}} \mathrm{o}(\mathrm{t}, \mathrm{z})=\sum \mathrm{Uo}_{\mathrm{i}}(\mathrm{t}, \mathrm{z}) \mathrm{f}_{\mathrm{i}}(\mathrm{t}, \mathrm{z})$

$\mathrm{U}(\mathrm{t}, \mathrm{z})=\int_{0}^{\mathrm{z}} \overline{\mathrm{U}} \mathrm{o}(\mathrm{t}, \mathrm{z}) \mathrm{dz}$

$\mathrm{U}(\mathrm{t}, 0)=0$

$\sum \mathrm{f}_{\mathrm{i}}=\sum \mathrm{X}_{\mathrm{i}} / \rho=1$

$\frac{d L(t)}{d t}=U(t, L)-\sigma(t)$

$\sigma(\mathrm{t})=\lambda \mathrm{L}(\mathrm{t})^{2}$

\subsubsection{Mass balance for the soluble compounds in the biofilm.}

Equations 11-13 describe the mass balance for the soluble components (i) in the biofilm $\left(\mathrm{S}_{\mathrm{i}}{ }^{\mathrm{f}}\right)$ and the boundary conditions: 
$215 \quad \frac{d S_{i}^{f}(t, z)}{d t}=D_{i}^{f} \frac{d^{2} S_{i}^{f}(t, z)}{d z^{2}}+r_{i}(t, z)$

$216 \mathrm{i}=\mathrm{F}, \mathrm{A}, \mathrm{NH}_{4}, \mathrm{PO}_{4}, \mathrm{NO}_{3}, \mathrm{O}_{2}, \mathrm{ND}$.

$217 \quad \frac{d S_{i}^{f}(t, 0)}{d z}=0$

$218 \quad \frac{d S_{i}^{f}(t, L)}{d z}=\frac{D_{i}^{W}}{D_{i}^{f} L_{l}}\left[S_{i}^{b}(t)-S_{i}^{f}(t, L)\right]$

219 The diffusion coefficients within the biofilm $\left(\mathrm{D}_{\mathrm{i}}{ }^{\mathrm{f}}\right)$ are supposed to be $80 \%$ of the 220 diffusion coefficient in water $\left(\mathrm{D}_{\mathrm{i}}{ }^{\mathrm{W}}\right)$ (Wanner and Gujer, 1986).

221 The model describes the flux of soluble compounds in the biofilm according to Fick's

222 first law

$223 \quad \mathrm{~J}_{\mathrm{i}}(\mathrm{t}, \mathrm{z})=-\mathrm{D}_{\mathrm{i}}^{\mathrm{f}} \frac{\mathrm{dS} \mathrm{S}_{\mathrm{i}}^{\mathrm{f}}(\mathrm{t}, \mathrm{z})}{\mathrm{dz}}$

224

225

\subsection{Bulk liquid model}

226

The MBBR reactor is modelled as a perfectly mixed reactor according to equations 15

227 and 16 (Mašic et al., 2010).

228

$V_{M B B R} \frac{d s_{i}^{b}(t)}{d t}=Q^{i n}\left(S_{i}^{\text {in }}-S_{i}^{b}\right)-J_{i}(t, z) A F+r_{i}(t) V_{M B B R}$

$229 \mathrm{i}=\mathrm{F}, \mathrm{A}, \mathrm{NH}_{4}, \mathrm{PO}_{4}, \mathrm{NO}_{3}$ and ND.

$230 \quad V_{M B B R} \frac{d X_{i}^{b}(t)}{d t}=Q^{i n}\left(X_{i}^{i n}-X_{i}\right)+\lambda L(t)^{2} A F \rho+r_{i}(t) V_{M B B R}$

$231 \mathrm{i}=\mathrm{S}, \mathrm{H}$, Aut, I and predators.

233 The model was built using the commercial software Aspen Custom Modeler ${ }^{\circledR}$ (ACM), 234 which allows models to be customized for specific processes. The technique used to 235 solve the system of equations is the method of lines (MOL), and the BFD1 method is 236 the discretization method. The evolution of the biofilm thickness leads to a "moving 
237 boundary” problem that requires that the biofilm thickness be normalized to 1 as described by Wanner and Gujer (1986).

239 The system of equations was iterated at time steps of $\Delta \mathrm{t}=0.1$ days until 30 days to

240 ensure that the biofilm thickness had reached a steady-state. The maximum number of

241 iterations was 100.

242 2.5. Model calibration

243 Biological wastewater treatment plants in the pulp and paper industry are designed for

244 COD removal (Rankin et al., 2007). This enables a rather simple strategy for model

245 calibration because only one predominant biological process exists: the degradation of

246 organic matter (Keskitalo et al., 2010), and it is necessary to change only a few model

247 parameters (Henze et al., 2000).

248 In this study, the parameters $i_{\mathrm{N}, \mathrm{BM}}, \mathrm{i}_{\mathrm{P}, \mathrm{BM}}, \mathrm{i}_{\mathrm{N}, \mathrm{XI}}$ and $\mathrm{i}_{\mathrm{P}, \mathrm{XI}}$ were adjusted at steady state 249 with average experimental data for each scenario. These four parameters are designated 250 in Table 4 as "calibrated parameters", and the other parameters were obtained from the 251 references. The corresponding parameters were estimated using the Aspen Custom 252 Modeler software, which allows rigorous models to be solved and parameters to be 253 estimated. The adjustment of the model parameters was carried out using an NL2SOL 254 algorithm for least-square minimization of the deviation between the experimental and 255 theoretical data.

\section{Experimental section: Pulp and paper full-scale MBBR plant}

257 The pulp and paper industry produces a considerable amount of wastewater of variable 258 characteristics depending on the production process and the quality of the final product 259 (Buyukkamaci and Koken, 2010). 
261 The MBBR treatment plant of the integrated cellulose and viscose manufacturing mill is

262 shown in Figure 3. The influent wastewater is coarsely screened to eliminate the larger 263 solids (> $6 \mathrm{~mm}$ ). An equalization tank with a volume of $1,600 \mathrm{~m}^{3}$ is used to adjust the 264 flow rate and introduce nutrients. Later, two aerobic MBBR reactors of a unit volume of $2655,331 \mathrm{~m}^{3}$ are employed in the treatment line.

266 Normally, the pulp and paper mill effluent contains low concentrations of nitrogen and 267 phosphorus, especially in the readily available forms of ammonium and orthophosphate. These nutrients must be added externally for efficient biological treatment (Kenny, 2010). In this study, nitrogen was added as urea with a nitrogen content of $18.4 \%$ and phosphorus as phosphoric acid with a phosphorus content of $23.7 \%$. Both were added to the equalization tank.

Oxygen is introduced in an MBBR reactor by means of blowers. For all of the experimental conditions, the dissolved oxygen concentration $\left(\mathrm{S}_{\mathrm{O} 2}\right)$ was constant in the bulk liquid at approximately $3 \mathrm{~g} / \mathrm{m}^{3}$ in $\mathrm{MBBR}_{1}$ and $5 \mathrm{~g} / \mathrm{m}^{3}$ in $\mathrm{MBBR}_{2}$. The blower aeration was controlled by a Programmable Logic Controller (PLC).

Both MBBR reactors were filled to 10\% (Zalakain and Manterola, 2011) with flat 277 shaped AnoxKaldnes ${ }^{\mathrm{TM}}$ carrier media type BiofilmChip P for biofilm growth. The carrier had an effective specific surface of $900 \mathrm{~m}^{2} / \mathrm{m}^{3}$, nominal dimensions of $45 \mathrm{~mm} \mathrm{x}$ $3 \mathrm{~mm}$, a weight of $174 \mathrm{~kg} / \mathrm{m}^{3}$ and specific gravity of $0.96-1.02 \mathrm{~g} / \mathrm{cm}^{3}$.

The dissolved oxygen $\left(\mathrm{S}_{\mathrm{O} 2}\right)$ in the bulk liquid for each MBBR reactor was monitored online by an optical oxygen sensor Oxymax W COS61, and the influent flow-rate (Q) 

10W.

285 The analysis of $\mathrm{COD}_{\mathrm{f}}, \mathrm{TN}, \mathrm{S}_{\mathrm{NO} 3}$ and $\mathrm{S}_{\mathrm{PO} 4}$ was performed using cuvette tests from Hach.

286 The $\mathrm{COD}_{\mathrm{f}}$ and TN samples were previously prepared in an LT 200 Hach Lange heating 287 block. The concentration values were obtained from the Hach Lange DR 2800 288 photometer.

The TSS determination was performed after a sample of bulk liquid was filtered on a Whatman glass micro fibre filter (GC/F). The dry weight was determined after the filter was dried at $105^{\circ} \mathrm{C}$ and weighed on a microbalance.

A Leitz Wetzlar ORTHOLUX 2 POL microscope was used to observe the biomass attached to the carriers and biomass in the bulk liquid.

\subsection{Stream characterization}

The MBBR plant operated under three different conditions (scenarios) distinguished by the origin of industrial wastewater (pulp and/or viscose), the flow rate of the influent, and the inlet concentrations of the $\mathrm{COD}_{\mathrm{f}}, \mathrm{TSS}, \mathrm{TN}, \mathrm{S}_{\mathrm{I}}, \mathrm{S}_{\mathrm{NO} 3}$ and $\mathrm{S}_{\mathrm{PO} 4}$. The total nitrogen of the influent was mostly organic biodegradable nitrogen from the added urea.

Scenario I ran continuously for eight months, scenario II for two months and scenario III for four months. These periods were determined by industrial production considerations. For the influent stream, daily grab samples were collected in scenario I, but in scenarios II and III, the sampling was 24-h mixed samples. For the outlet MBBR 1 and $\mathrm{MBBR}_{2}$ streams in all scenarios, grab samples were collected in situ during operation. All of the samples collected were analysed to determinate the COD and TSS concentration, but the TN, $\mathrm{S}_{\mathrm{NO}}$ and $\mathrm{S}_{\mathrm{PO} 4}$ were analysed in half of the samples. 
Table 5 shows the average influent flow rate and concentrations for each scenario (i.e., stable operational conditions). The data are expressed using different reference values (q, s, c, n and p) to maintain the confidentiality of the information. Even though the inlet stream originated from industrial production, the concentration of the compounds was quite stable during the entire run time in each scenario; however, variations in the inlet concentrations lower than $15 \%$ occurred in scenarios I and II and lower than $25 \%$ in scenario III.

A previous study using the same wastewater (Zalakain and Manterola, 2011) showed that in the influent, the higher the $\mathrm{COD}_{\mathrm{f}}$, the higher is $\mathrm{S}_{\mathrm{I}}$. In this study, it is assumed that $\mathrm{S}_{\mathrm{I}}$ in the influent is $25 \%$ of the $\mathrm{COD}_{\mathrm{f}}$ in scenarios I and II and $15 \%$ in scenario III.

\section{Results and discussion}

4.1. Simulated and experimental results for the full-scale MBBR plant

The simulation of the outlet stream concentration from the full-scale MBBR plant discussed in section 3.1 for the influent stream detailed in section 3.3 was carried out using the model proposed in section 2. The plant consisted of two in-series MBBR reactors. Because the same type of reactors are used in the plant, the same model is used to simulate the two MBBR units.

Figures 4 and 5 show the experimental and simulated results for the $\mathrm{COD}_{\mathrm{f}}$ and $\mathrm{TSS}$ for $\mathrm{MBBR}_{1}$ and $\mathrm{MBBR}_{2}$, respectively, during the operation of the inlet stream treatment. Good concordance between experimental and simulated values was observed, as seen in Figures 4 and 5. The standard deviations (SD) between the experimental and simulated concentrations of $\mathrm{COD}_{\mathrm{f}}$ and TSS are lower than $10 \%$ for the three scenarios (Table 6). 
The similar behaviour of the experimental $\left(\mathrm{C}_{\exp }\right)$ and simulated $\left(\mathrm{C}_{\text {sim }}\right)$ concentration

329 values with time and the SD values lower than $15 \%$ obtained in the three scenarios confirm the validity of the model.

Figure 4 indicates an average $\mathrm{COD}_{\mathrm{f}}$ removal percentage of approximately $42 \%-65 \%$ in $\mathrm{MBBR}_{1}$ and only $14-21 \%$ in $\mathrm{MBBR}_{2}$. In $\mathrm{MBBR}_{2}$ the $\mathrm{COD}_{\mathrm{f}}$ removal percentage was much lower than for $\mathrm{MBBR}_{1}$ because most of the readily biodegradable components $\left(\mathrm{S}_{\mathrm{F}}\right)$ from the influent were consumed by $\mathrm{MBBR}_{1}$.

An important increase in the TSS in $\mathrm{MBBR}_{1}$ in all three scenarios due to cell growth and the detachment of the biomass from the carriers is observed in Figure 5 because heterotrophic growth was the predominant process studied (Shubert et al., 2013). In scenario II, a slight increase in the TSS was observed in $\mathrm{MBBR}_{2}$; however, a nontypical slight decrease was observed in scenarios I and III in $\mathrm{MBBR}_{2}$.

Table 7 shows the average experimental concentrations of total nitrogen (TN) and inorganic soluble phosphorous $\left(\mathrm{S}_{\mathrm{PO} 4}\right)$ in the bulk liquid for each scenario. In scenarios I and III, the average values decreased sharply in $\mathrm{MBBR}_{1}$ and increased slightly in $\mathrm{MBBR}_{2}$ because of nutrient regeneration by the predation process. Such an increase has been observed in other works such as Lidblom et al., 2003, Rankin et al., 2007, and Tamis et al., 2011. However in scenario II, a sharp decrease in $\mathrm{MBBR}_{1}$ occurred, but no increase was seen in $\mathrm{MBBR}_{2}$.

Simulated values for $\mathrm{TN}$ and $\mathrm{S}_{\mathrm{PO}}$ in the bulk liquid were also obtained from the integrated model proposed in this study. The standard deviations between the experimental and simulated concentrations of TN and S $_{\text {PO4 }}$ are shown in Table 6. In the three scenarios, SD values lower than $15 \%$ were obtained for $\mathrm{TN}$ and $\mathrm{S}_{\mathrm{PO}}$, but these values are higher than the standard deviations of $\mathrm{COD}_{\mathrm{f}}$ and TSS. The higher SD values 
352 are probably due to the lower number of experimental nitrogen and phosphorous 353 samples.

354 Table 8 shows the average experimental values of SCLR and Soluble COD Removal 355 Rate (SCRR) for both MBBR reactors. High SCLR values were observed in all 356 scenarios at the inlet stream of $\mathrm{MBBR}_{1}\left(84-59 \mathrm{~g} \mathrm{COD} / \mathrm{m}^{2}\right.$ day) and high SCRR values 357 (70-38 g COD $/ \mathrm{m}^{2}$ day) due to heterotrophic growth being the predominant process 358 (Shubert et al., 2013). The last columns in Table 8 summarize the occurrence of 359 hydrolysis and predator growth in each MBBR for each scenario according to Figure 2. 360 At the $\mathrm{MBBR}_{2}$, low values of SCLR are observed in scenarios I and III and the hydrolysis process and predator growth process are significant, but higher values of SCLR in scenario II imply that hydrolysis and predator growth are negligible (Helness and Ødegaard, 2006, Shubert et al., 2013, Ødegaard, 1999, Villareal et al., 1975, Canale, 1973). Moreover, the presence of predator microorganisms such as ciliates was observed microscopically in the $\mathrm{MBBR}_{2}$ reactor in scenarios I and III.

Therefore, two MBBR reactors in-series are used in this work that can be considered as a two-stage system. The first stage at $\mathrm{MBBR}_{1}$ is the bacterial stage, and the second stage at $\mathrm{MBBR}_{2}$ is the bacterial-predator stage because at this second stage, the source food is composed of the bacteria that leave $\mathrm{MBBR}_{1}$ and a low COD concentration.

Table 9 shows a comparison between experimental and simulated values in $\mathrm{MBBR}_{2}$ when the predation and hydrolysis were switched on and off at steady state in scenarios

372 I and III because predation and hydrolysis occur in these scenarios. The simulated 373 values were similar to the experimental values when the predation and hydrolysis were 374 switched on. 
376 Steady-state growth of microorganisms occurred after 6 days, and the simulated results

377 for the biofilm in this section were obtained once a steady state had occurred.

378 The spatial distribution of the microorganism groups in a steady-state biofilm was 379 simulated by the specific growth rate $\mathrm{Uo}_{\mathrm{i}}$. The simulated values of biofilm thickness 380 (L)-and biomass per unit area (BM) are shown in Table 10. The BM values were in the 381 range of values found in the literature, ranging from $4 \mathrm{~g} \mathrm{TSS} / \mathrm{m}^{2}$ day (Andreottola et al., 2003) to 16 g TSS/m²day (Shubert et al., 2013), depending on the $\mathrm{COD}_{\mathrm{f}}$ removal.

First, as expected, a correspondence was observed between BM and L. The thickness of the biofilm in $\mathrm{MBBR}_{1}$ in scenario I was the highest because the SCRR in scenario I has the highest value (see Table 8).

A greater biofilm depth in $\mathrm{MBBR}_{1}$ than in $\mathrm{MBBR}_{2}$ was obtained for scenarios I and II because the greater microbial activity occurred in $\mathrm{MBBR}_{1}$, where most of the readily biodegradable components from the influent $\left(\mathrm{S}_{\mathrm{F}}\right)$ were consumed. However, in scenario III, the thickness of the biofilm at $\mathrm{MBBR}_{2}$ was slightly greater than in $\mathrm{MBBR}_{1}$ due to the high (>6 hours) hydraulic retention time (HRT) in scenario III, and consequently, the hydrolysis percentage was also high. Higher hydrolysis in the bulk liquid means that more readily biodegradable material $\left(\mathrm{S}_{\mathrm{F}}\right)$ was available for the biofilm microorganisms (Rohold and Harremoës, 1993; Larsen and Harremoës, 1994) and that the thickness was greater (Schubert et al., 2013). It is important to note that the HRT was nearly double in scenario III than in scenarios I and II (Table 5).

Figure 6 shows the volume fraction of the spatial distribution of the microorganism groups $\left(f_{S}, f_{I}, f_{H}, f_{\text {Aut }}\right.$ and $\left.f_{\text {predators }}\right)$, the oxygen concentration profiles $\left(\mathrm{S}_{\mathrm{O} 2}\right)$ in the biofilm vs. the biofilm depth for the three scenarios and the two MBBR reactors. An analysis of Figure 6 shows the following aspects: 
- Autotrophic microorganisms ( $\mathrm{f}_{\text {Aut }}$ ) do not appear in the spatial distribution of the biofilm because the SCLR (Table 8) is very high, and therefore, heterotrophic microorganisms are predominant. The heterotrophic biomass has a higher specific 
matter in the outer side of the biofilm in $\mathrm{MBBR}_{2}$ is twice that in $\mathrm{MBBR}_{1}$ in scenarios I and III because of predation. However, in scenario II, predation does not occur, and the volume fraction of inert matter in the outer side of the biofilm is approximately the same in both $\mathrm{MBBR}_{1}$ and $\mathrm{MBBR}_{2}$.

- The proposed model allows the oxygen ( $\left.\mathrm{S}_{\mathrm{O} 2}\right)$ concentration in the biofilm to be simulated. In scenarios I and III, the oxygen concentration approaches zero because it is consumed by heterotrophic microorganisms $\left(\mathrm{f}_{\mathrm{H}}\right)$, and consequently, oxygen is the limiting substrate. However, in scenario II, up to $507 \mu \mathrm{m}$ in $\mathrm{MBBR}_{1}$ and up to $394 \mu \mathrm{m}$ in $\mathrm{MBBR}_{2}$, the oxygen remains constant with an approximate value of 1 $\mathrm{g} / \mathrm{m}^{3}$ in $\mathrm{MBBR}_{1}$ and $4 \mathrm{~g} / \mathrm{m}^{3}$ in $\mathrm{MBBR}_{2}$; therefore, it is not a limiting substrate. In addition to aerobic conditions, the heterotrophic microorganisms can grow under anoxic and anaerobic conditions. Other authors such as Lee and Park, 2007, confirm that the heterotrophic microorganisms $\left(\mathrm{f}_{\mathrm{H}}\right)$ can still grow under oxygenlimited conditions with nitrate as an alternative electron acceptor. In $\mathrm{MBBR}_{1}$ in scenario III, heterotrophic microorganisms $\left(\mathrm{f}_{\mathrm{H}}\right)$ were present under anoxic and anaerobic conditions as indicated by a small volumetric fraction of $\mathrm{f}_{\mathrm{H}}$ appearing at the maximum depth of the biofilm.

Figure 7 shows the simulated concentration depth profiles of $\mathrm{COD}_{\mathrm{f}}$ and $\mathrm{S}_{\mathrm{PO} 4}$ in the biofilm, and it is evident that phosphorous was the limiting substrate in scenario II because the concentration approached zero at a depth of $507 \mu \mathrm{m}$ in $\mathrm{MBBR}_{1}$ and at $394 \mu \mathrm{m}$ in $\mathrm{MBBR}_{2}$. It must be mentioned that scenario II had the lowest amount of phosphorus added to the influent (Rankin et al., 2007), as is shown in Table 5. In scenarios I and III, $\mathrm{S}_{\mathrm{PO} 4}$ is not zero, although oxygen was the limiting substrate in the biofilm. 
The distribution of microorganism groups and $\mathrm{COD}_{\mathrm{f}}$ in the bulk liquid during a 451 dynamic simulation of 30 days was obtained from the proposed model. Figure 8 shows 452 a simulation of the evolution of $\mathrm{COD}_{\mathrm{f}}$ in the bulk liquid of $\mathrm{MBBR}_{1}$ and $\mathrm{MBBR}_{2}$ with 453 time for each scenario. An initial rapid decrease in the $\mathrm{COD}_{\mathrm{f}}$ concentration was observed and a steady-state was reached after 6 days due to rapid biofilm growth. This rapid biofilm growth was also found in other studies such as Lee and Park, 2007 and Zalakain and Manterola, 2011. The same behaviour was observed in all scenarios.

Figure 9 shows the simulated values of the concentration of heterotrophic microorganisms $\left(\mathrm{X}_{\mathrm{H}}\right)$, slowly biodegradable compounds $\left(\mathrm{X}_{\mathrm{S}}\right)$, inert matter $\left(\mathrm{X}_{\mathrm{I}}\right)$, and predator microorganisms ( $\mathrm{X}_{\text {predators}}$ ) in the bulk liquid of $\mathrm{MBBR}_{1}$ and $\mathrm{MBBR}_{2}$ for the three scenarios at steady-state. These simulated values show a decrease in the slowly biodegradable organic compounds $\left(\mathrm{X}_{\mathrm{S}}\right)$ in $\mathrm{MBBR}_{2}$ for scenarios I and III. This decrease is due to the hydrolysis of $\mathrm{X}_{\mathrm{S}}$ to $\mathrm{S}_{\mathrm{F}}$ and was $78 \%$ in scenario I and $86 \%$ in scenario III. The percentage of $\mathrm{X}_{\mathrm{S}}$ converted by hydrolysis is higher in scenario III because the HRT was nearly double that in scenario I. Shubert et al., 2013, studied two MBBR in series with different TRH values and concluded that the lower the TRH, the less hydrolysis occurs. However, in scenario II, the value of $\mathrm{X}_{\mathrm{S}}$ increases in $\mathrm{MBBR}_{2}$ because hydrolysis is negligible (Figure 2).

Figure 9 shows that predator microorganisms ( $\left.\mathrm{X}_{\text {predators }}\right)$ appear in the bulk liquid of $\mathrm{MBBR}_{2}$ in scenarios I and III. The presence of predator microorganisms causes a decrease in the heterotrophic biomass $\left(\mathrm{X}_{\mathrm{H}}\right)$ in $\mathrm{MBBR}_{2}$ of $16.4 \%$ and $26.3 \%$ for

471 scenarios I and III, respectively. Moussa et al., 2005, also observed a decrease in the 472 active biomass fraction $\left(\mathrm{X}_{\mathrm{H}}\right)$ when predators were present. 
473 The reduced heterotrophic biomass in the bulk liquid $\left(\mathrm{X}_{\mathrm{H}}\right)$ and in the biofilm $\left(\mathrm{f}_{\mathrm{H}}\right)$

474 caused by predation leads to an interesting phenomenon related to the total nitrogen and

475 phosphorous in the bulk liquid (TN and $\mathrm{S}_{\mathrm{PO} 4}$ ). $\mathrm{S}_{\mathrm{PO} 4}$ and $\mathrm{TN}$ from the influent are

476 consumed by heterotrophic microorganisms $\left(\mathrm{X}_{\mathrm{H}}\right.$ and $\left.\mathrm{f}_{\mathrm{H}}\right)$, and later, heterotrophic

477 microorganism are consumed by the predators, then $\mathrm{S}_{\mathrm{PO} 4}$ and $\mathrm{S}_{\mathrm{NH} 4}$ are regenerated in

478 the bulk liquid and eventually are available for the growth of heterotrophic 479 microorganisms $\left(\mathrm{X}_{\mathrm{H}}\right.$ and $\mathrm{f}_{\mathrm{H}}$ ) (Lindblom, 2003). The simulated and experimental values 480 show an increase in phosphorus and total nitrogen ( $\mathrm{S}_{\mathrm{PO} 4}$ and $\mathrm{TN}$ ) in $\mathrm{MBBR}_{2}$ in 481 scenarios I and III (Table 7) due to predation. This increase has also been seen in other 482 studies such as Tamis et al., 2011.

483 Finally, Figure 10 shows the evolution of the simulated TSS with time in the three scenarios in the bulk liquid. It is noteworthy that the sum of all of the simulated TSS concentrations was lower in $\mathrm{MBBR}_{2}$ than in $\mathrm{MBBR}_{1}$ by $5.7 \%$ in scenario $\mathrm{I}$ and by $12.9 \%$ in scenario III due to hydrolysis and predator growth.

Predation is a key factor in the estimation of actual sludge production and nutrient requirements in wastewater treatment systems including MBBR processes, and a validated model describing these phenomena could be very helpful for designers and operators. In this study, different amounts of nutrients were added in the inlet streams; taking into account the high cost of these nutrients, future studies will use the model to optimize the nutrient amounts added to the MBBR plant under study.

\section{Conclusions}

The integrated MBBR model for COD removal presented in this paper is a multispecies and multi-substrate mechanistic biofilm model that considers a) the hydrolysis of slowly biodegradable compounds in the bulk liquid and b) the growth of predator 
497 microorganisms in the bulk liquid and in biofilm in terms of the values of the soluble 498 biodegradable COD loading rate (SCLR). This model can be used for different types of 499 wastewater under different operational conditions.

500 The validity of the proposed integrated model was confirmed using wastewater from the 501 cellulose and viscose industry with two in-series MBBR industrial plant. Simulated 502 values of $\mathrm{COD}_{\mathrm{f}}, \mathrm{TSS}$, TN and $\mathrm{S}_{\mathrm{PO} 4}$ obtained by the integrated mathematical model in 503 the full-scale MBBR plant were compared with experimental values. The standard 504 deviations between the simulated and experimental concentrations for the outlet streams 505 in $\mathrm{MBBR}_{1}$ and $\mathrm{MBBR}_{2}$ are lower than $15 \%$ for three different scenarios.

506 Predator growth was confirmed under two different operational conditions and, in 507 combination with hydrolysis, allows the interpretation of non-typical results from $508 \mathrm{MBBR}_{2}$ as decreases in TSS in the bulk liquid.

509 The proposed model allowed simulation of the oxygen and phosphorous concentrations 510 in the biofilm and determined the limiting substrate in the biofilm.

511 The reduced heterotrophic biomass in the bulk liquid as in the biofilm caused by 512 predation leads to an interesting phenomenon: the concentration of inorganic soluble 513 phosphorous and the total nitrogen concentration in the influent were consumed by 514 heterotrophic microorganisms, and when heterotrophic microorganisms were in turn 515 consumed by predators, the phosphorous and total nitrogen concentrations were 516 regenerated to the bulk liquid and eventually available for the growth of heterotrophic 517 microorganisms. 
518 In the near future, the proposed model will be used to optimize the operational cost of

519 the wastewater treatment plant by optimizing the nutrient dosage for different 520 operational conditions.

522 Acknowledgements

523 The authors would like to thank SNIACE Company for their help and support during 524 the wastewater sampling and characterization at industrial plant.

\section{6. References}

526 • Andreottola G., Foladori P., Gatti, G., Nardelli P, Pettena M., Ragazzi M., 2003, 527 Upgrading of a small overloaded activated sludge plant using a MBBR 528 system, Journal of Environmental Science and Health - Part A Toxic/Hazardous $529 \quad$ Substances and Environmental Engineering 38(10), 2317-2328.

- Barwal A., Chaudhary R., 2014. To study the performance of biocarriers in moving bed 531 biofilm reactor (MBBR) technology and kinetics of biofilm for retrofitting the existing 532 aerobic treatment systems: a review. Rev. Environ. Sci. Biotechnol., 13, 285-299.

• Boltz J.P., Morgenroth E., Brockmann D., Bott C., Gellner W.J., Vanrolleghem P.A., 534 2011. Systematic evaluation of biofilm models for engineering practice: components and 535 critical assumptions. Water Sci. Technol. 64(4), 930-944.

536 • Borkar R., Gulhane M., Kotangale A., 2013. Moving Bed Biofilm Reactor - A New 537 Perspective in Wastewater Treatment. IOSR-JESTFT, 6(6), 15-21.

538 • Buyukkamaci N., Koken E., 2010.Economic evaluation of alternative wastewater 539 treatment plant options for pulp and paper industry. Sci. Total Environ.,408 (24), 6070540 6078. 
541 - Canale, R.P., 1973. Experimental and Mathematical Modeling Studies of Protozoan 542 Predation on Bacteria. Biotechnol. Bioeng., 15, 707-728.

543 • Fried J., Mayr G., Berger H., Traunspurger W., Psennere R., Lemmerf H., 2000.

544 Monitoring protozoa and metazoa biofilm communities for assessing wastewater quality

545 impact and reactor up-scaling effects. Water Sci. Technol., 45(4-5), 309-316.

546 • Geesey G.G., 1994. Biofouling/biocorrosion in industrial water systems. Biofouling and 547 Biocorrosion in Industrial Water Systems. Geesey, G.G., Lewandowski, Z. \& Flemming, $548 \quad$ H.C. Boca Raton: Lewis Publishers.

549 • Goode C., 2010. Understanding biosolids dynamics in a moving bed biofilm reactor. PhD 550 thesis, University of Toronto, Canada.

551 • Hao X., Wang Q., Cao Y., van Loosdrecht M.C.M., 2011. Evaluating sludge 552 minimization caused by predation and viral infection based on the extended activated 553 sludge model No. 2d. Water Res., 45, 5130-5140.

554 • Helness H., Ødegaard H., 2005. Biological phosphorus and nitrogen removal from 555 municipal wastewater with a moving bed biofilm reactor. Proc. IWA Specialized 556 Conference Nutrient Management in Wastewater Treatment Processes and Recycle 557 Streams, Krakow, 19-21, 435-444.

558 •Henze M., Gujer W., Mino T., van Loosdrecht M., 2000. Activated sludge models 559 ASM1, ASM2, ASM2D and ASM3. IWA Scientific and Technical Report No.9. IWA 560 Publishing, London, UK.

- Hosseini S.H., Borghei S.M., 2005. The treatment of phenolic wastewater using a moving 562 bed bio-reactor. Process Biochem., 40 (3-4), 1027-1031. 
- Jeppsson U., 1996. Modelling aspects of wastewater treatment processes, Ph.D., 566 Department of Industrial Electrical Engineering and Automation (IEA), Lund Institute of 567 Technology, Sweden.

568 • Kaindl N., 2010. Upgrading of an activated sludge wastewater treatment plant by adding 569 a moving bed biofilm reactor as pretreatment and ozonation followed by biofiltration for 570 enhanced COD reduction: design and operation experience. Water Sci. Technol., 62(11), $5712710-2729$.

572 • Kenny R., 2010. Nutrient optimization for pulp \& paper wastewater treatment plants - An 573 opportunity for major cost savings. Pulp Pap-Canada, 111(2), 20-25.

574 • Keskitalo J., La Cour Jansen, J., Leiviskä, K., 2010, Calibration and validation of a 575 modified ASM1 using long-term simulation of a full-scale pulp mill wastewater treatment 576 plant, Environmental Technology, 31(5), 555-566.

577 • Kinner N.E., Curds C.R., 1987, Development of protozoan and metazoan communities in 578 rotating biological contactor biofilms. War. Res., 21-4, 481-490.

579 • Larsen T.A., Harremoës P., 1994. Degradation mechanisms of colloidal organic matter in 580 biofilm reactors. Water Res., 28(6), 1443-1452.

581 • Lee M.W., Park J.M., 2007. One-dimensional mixed-culture biofilm model considering 582 different space occupancies of particulate components. Water Res., 41(19), 4317-4328.

583 • Lei G., Ren H., Ding L., Wang F., Zhang X., 2010. A full scale biological treatment 584 system application in the treated wastewater of pharmaceutical industrial 585 park. Bioresource Techno., 101 (15), 5852-5861. 
- Lindblom E., 2003. Dynamic Modelling of Nutrient Deficient Wastewater Treatment Processes. Master thesis, Department of Industrial Electrical Engineering and Automation, Lund University, Sweden.

• Mašic A., Bengtsson J., Christensson M., 2010. Measuring and modeling the oxygen profile in a nitrifying Moving Bed Biofilm Reactor, Math. Biosci., 227, 1-11.

- Mašic A., 2013. Investigation of a biofilm reactor model with suspended biomass. Ph.D. Thesis, Lund University, Sweden.

• Morgenroth E, Kommedal R, Harremoës P., 2002. Processes and modeling of hydrolysis of particulate organic matter in aerobic wastewater treatment- a review. Water Sci. Technol., 45(6): 25-40.

- Moussa M., Hooijmans C., Lubberding H., Gijzen H., van Loosdrecht M., 2005. Modelling nitrification, heterotrophic growth and predation in activated sludge. Water Res., 39(20), 5080-5098.

• Ni B.J., Rittmann B.E., Han-Qing Yu H.Q., 2009. Modeling Predation Processes in Activated Sludge. Biotechnol. Bioeng., 5 (6), 1021-1030.

• Ni B.J., Sheng G.P., Yu H.Q., 2011. Model-based characterization of endogenous maintenance, cell death and predation processes of activated sludge in sequencing batch reactors. Chem. Eng. Sci., 66, 747-754.

• Ødegaard H., 1999. The moving bed biofilm reactor. In: Igarashi T., Watanabe Y., Tambo N. (eds.).Water environmental engineering and reuse of water. Hokkaido Press, Sapporo, pp 250-305.

- Ødegaard H., 2006. Innovations in wastewater treatment: the moving bed biofilm process. Water Sci. Technol. 53 (9), 17-33 
- Qiqi Y., Qiang H., Husham T., 2012. Review on Moving Bed Biofilm Processes. Pakistan J. of Nutr., 11(9), 706-713.

- Rankin A., Van Aert M., Welander T., Malmqvist A., 2007. Low sludge yield Bio-film Activated Sludge (BAS) Upgrade- Quesnel River Pulp Co. Tappi J. 6(5), 17-22.

• Remy C., Boulestreau M., Lesjean B., 2014. Proof of concept for a new energy-positive wastewater treatment scheme. Water Sci. Technol. 70 (10), 1709-1716.

• Rohold L., Harremoës P., 1993. Degradation of non-diffusible organic matter in biofilm reactors. Water Res., 27(11), 1689-1691.

• Ruiken C., Breuer G., Klaversma E., Santiago T., van Loosdrecht, M.C.M., 2013. Sieving wastewater - Cellulose recovery, economic and energy evaluation, Water Res., 47(1), 4348.

• Rusten B., McCoy M., Proctor R., Siljudalen J.G., 1998. The innovative moving bed biofilm reactor/solids contact reaeration process for secondary treatment of municipal wastewater. Water Environ. Res., 70(5), 1083-1089.

- Rusten B., Eikebrokk B., Ulgenes Y., Lygren E., 2006. Design and operations of the Kaldnes moving bed biofilm reactors. Aquacult. Eng., 34, 322-331.

- Schubert R.L., Boulestreau M., Christensson M., Lesjean B., 2013. Novel wastewater process scheme for maximum COD extraction: high load MBBR followed by microsieve filtration, $9^{\text {th }}$ International Conference on Biofilm Reactors, May 28-31, Paris, France.

- Swamy N.K., Singh P., Sarethy I.P., 2011. Aerobic and anaerobic treatment of paper industry wastewater. Res. Environ. Life Sci., 4(4), 141-148.

• Tamis J., van Schouwenburg G., Kleerebezem R., van Loosdrecht, M.C.M., 2011. A full scale worm reactor for efficient sludge reduction by predation in a wastewater treatment plant. Water Res. 45 (18), 5916-5924. 
- Vanhooren H., 2001. Modelling for optimization of biofilm wastewater treatment processes: a complexity compromise. Ph.D. Thesis, Faculty of Agricultural and Applied Biological Sciences. Ghent University.

•van Haandel A., van der Lubbe J., Handbook of Biological Wastewater Treatment, 2012 Editor IWA., Second Edition. 2012.

• van Loosdrecht M.C.M., Henze, M., 1999. Maintenance, endogenous respiration, lysis, decay and predation. Water Sci. Technol. 39, 107-117.

•van Loosdrecht M.C.M., Heijnen J.J., Eberl H.J., Kreft J.U., Picioreanu, C., 2002. Mathematical modelling of biofilm structures. Antonie Van Leeuwenhoek 81, 245- 256.

• Villareal E., Canale R.P., Akcasu Z., 1975. A multigroup model for predator-prey interactions. Biotechnol. Bioeng., 17(9), 1269-1290.

•Wanner O., Gujer W., 1986. A multispecies biofilm model. Biotechnol. Bioeng., 28, 314328.

•Wanner O., 1996. Modelling of biofilms. Biofouling 10, 31-41.

•Wanner O., Ebert H.J., Morgenroth E., Noguera D., Picioreanu C., Rittmann B.E., Van Loosdrecht, M.C.M., 2006. Mathematical modeling of biofilms. IWA Scientific and Technical Report No. 18, IWA Task Group on Biofilm Modeling.

- Zalakain G., Manterola G., 2011. Biological treatment of the Sniace wastewater treatment plant by the BAS process. Tratamiento biológico de la EDAR de Sniace mediante el proceso BAS. Tecnología del agua, 335: 2-8. 